\title{
D6 protein kinase in root xylem benefiting resistance to Fusarium reveals infection and defense mechanisms in tung trees
}

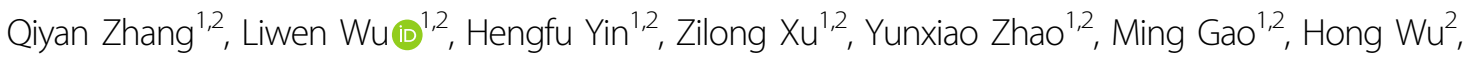
Yicun Chen $\mathbb{1}^{1,2 \times}$ and Yangdong Wang ${ }^{1,2 \times}$

\begin{abstract}
Fusarium oxysporum, a global soil-borne pathogen, causes severe disease in various cultivated plants. The mechanism underlying infection and resistance remains largely elusive. Vernicia fordii, known as the tung tree, suffers from disease caused by F. oxysporum f. sp. fordiis (Fof-1), while its sister species V. montana displays high resistance to Fof- 1 . To investigate the process of infection and resistance ability, we demonstrated that Fof- 1 can penetrate the epidermis of root hairs and then centripetally invade the cortex and phloem in both species. Furthermore, Fof-1 spread upwards through the root xylem in susceptible $V$. fordii trees, whereas it failed to infect the root xylem in resistant $V$. montana trees. We found that D6 PROTEIN KINASE LIKE 2 (VmD6PKL2) was specifically expressed in the lateral root xylem and was induced after Fof-1 infection in resistant trees. Transgenic analysis in Arabidopsis and tomato revealed that $V m D 6 P K L 2$ significantly enhanced resistance in both species, whereas the $16 \mathrm{pk} / 2$ mutant displayed reduced resistance against Fof-1. Additionally, VmD6PKL2 was identified to interact directly with synaptotagmin (VmSYT3), which is specifically expressed in the root xylem and mediates the negative regulation responding to Fof-1. Our data suggested that VmD6PKL2 could act as a resistance gene against Fof-1 through suppression of VmSYT3-mediated negative regulation in the lateral root xylem of the resistant species. These findings provide novel insight into Fusarium wilt resistance in plants.
\end{abstract}

\section{Introduction}

Fusarium oxysporum, one of the top ten fungal plant pathogens ${ }^{1}$, is the causal agent of vascular wilt diseases of more than 120 plant species, provoking severe losses to crop production and the world economy ${ }^{2,3}$. Colonization of plants by $F$. oxysporum leads to necrosis of the infected tissues, collapse of vascular vessels, stunting, progressive wilting and defoliation of leaves, and decay of the plant ${ }^{4}$. As a ubiquitous soil-borne pathogen, $F$. oxysporum can survive in the soil for up to 30 years as durable

Correspondence: Yicun Chen (chenyc@caf.ac.cn) or

Yangdong Wang (wangyangdong@caf.ac.cn)

${ }^{1}$ State Key Laboratory of Tree Genetics and Breeding, Chinese Academy of Forestry, Beijing 100091, China

${ }^{2}$ Research Institute of Subtropical Forestry, Chinese Academy of Forestry,

Hangzhou 311400 Zhejiang Province, China chlamydospores ${ }^{5}$. At present, the mechanisms of infection and resistance are largely unknown; as a result, no efficient ways can completely control the outbreak and spread of Fusarium wilt.

Vernicia (Euphorbiaceae) species are promising industrial oil trees that produce tung oil from fruits. Vernicia fordii and Vernicia montana are the two main cultivated species. Compared to $V$. montana, $V$. fordii displays faster maturation periods and superior oil characteristics ${ }^{6}$. Therefore, oil refined from the seeds of $V$. fordii has been widely applied for the production of paints and coatings, inks, lubricants, synthetic rubber and biodiesel ${ }^{7}$. However, tung wilt disease caused by $F$. oxysporum f. sp. fordiis (Fof-1) has caused devastating damage to the growth and development of $V$. fordii. In contrast, $V$. montana shows notable resistance against Fusarium wilt disease ${ }^{8}$. However, the resistance

\section{(c) The Author(s) 2021}

(c) Open Access This article is licensed under a Creative Commons Attribution 4.0 International License, which permits use, sharing, adaptation, distribution and reproduction c. in any medium or format, as long as you give appropriate credit to the original author(s) and the source, provide a link to the Creative Commons license, and indicate if changes were made. The images or other third party material in this article are included in the article's Creative Commons license, unless indicated otherwise in a credit line to the material. If material is not included in the article's Creative Commons license and your intended use is not permitted by statutory regulation or exceeds the permitted use, you will need to obtain permission directly from the copyright holder. To view a copy of this license, visit http://creativecommons.org/licenses/by/4.0/. 
mechanism of Vernicia against Fusarium remains largely unknown.

A comprehensive understanding of the interaction between plants and pathogenic Fusarium is crucial for elucidating the molecular basis of disease resistance and is invaluable for Fusarium wilt disease management ${ }^{9}$. This lack of a comprehensive understanding has driven a considerable amount of research on plant disease for many years ${ }^{10}$. However, knowledge about host-pathogen interactions in wilt disease is limited. Due to the complexity and potential variability of resistance to $F$. oxysporum among different plant species ${ }^{4}$, investigations toward the recognition of effective barriers that can limit pathogen invasion and the identification of novel resistance-related factors in forest trees should be urgently developed.

The Vernicia genus contains both resistant and susceptible species, which share high similarities in morphology, anatomy and karyotype. Therefore, it is an appreciated model for the investigation of the infection and resistance mechanism of Fusarium wilt disease. To reveal the detailed infection process of soil-born Fusarium in plants and the possible resistance mechanism of plants, we first conducted an anatomic analysis of roots between susceptible and resistant Vernicia species and found that the pathogen Fof-1 was hindered in the root xylem of resistant $V$. montana. Based on our previous comparative transcriptomes ${ }^{7}$, we revealed that several candidate hub genes might be involved in resistance to Fof-1 infection. These hub genes included D6 PROTEIN KINASE LIKE 2 (D6PKL2), LRR-RLK2 CLAVATA2, diacylglycerol kinase (DGK), ETHYLENE RESPONSE FACTOR72 (ERF72) and glycosyltransferase (GT). Among these hub genes, CLAVATA2, DGK, ERF72 and GT1 have all been reportedly involved in pathogen resistance ${ }^{11-14}$. Specifically, it is well known that D6PKL2 is involved in lateral root formation and root epidermal planar polarity ${ }^{15,16}$. However, whether D6PKL2 is involved in disease resistance is poorly understood. Here, we revealed that D6PKL2 was specifically expressed in root xylem and induced in response to Fof- 1 infection in resistant $V$. montana. More importantly, the resistance ability of $V m D 6 P K L 2$ to Fof-1 in Arabidopsis and tomatoes was further verified. The study illuminates crucial information contributing to the control of Fusarium wilt disease in plants.

\section{Results}

Fof-1 failed to infect the lateral root xylem in the resistant V. montana trees

To track the infection process, the Fof-1 pathogen was transformed with the GFP (Green fluorescent protein) label. All positive transformants showed the expression of GFP and $h p h$ (Fig. S1a, b). In addition, the mycelium and conidium exhibited high fluorescence expression (Fig. S1c, d). After five subcultures, transformants named 3-1 and 3-10 showed stable GFP expression, similar phenotypes, and pathogenicity to the wild-type strain (Fig. S1e). Transformant 3-1 was selected for further infection experiments.

To explore the effective position or component preventing pathogen infection in resistant $V$. montana, the detailed infection process of Fof-1 in $V$. fordii and $V$. montana was comparatively observed (Fig. 1 ). Within $24 \mathrm{~h}$ after infection with Fof-1, spore germination and mycelium colonization were observed on the epidermis in both susceptible and resistant species (Fig. 1b, f; Fig. S2a, e). The hyphae initially attached themselves to the lateral root surface and grew along the junctions of epidermal cells to form a dense network intermingled with root hairs. Following surface colonization, direct penetration occurred primarily at the root hairs and their emergence sites of lateral roots (Fig. S2b, f). Hyphae became swollen, and appressorium-like structures were observed (Fig. S2c, f). At 3 dpi (days post-infection), the fungi propagated either intracellularly or intercellularly in the cortex of lateral roots in both $V$. fordii and $V$. montana (Fig. 1c, g). At 5 dpi, Fof- 1 continued to grow centripetally and invaded the phloem and xylem of lateral roots in susceptible $V$. fordii (Fig. 1d, e), while the hyphae extended only to the phloem in resistant $V$. montana (Fig. 1h, i). At 8 dpi, Fof-1 spread longitudinally to the main roots through the xylem of the lateral root in susceptible $V$. fordii. The hyphae were confined to the xylem vessels of the main root (Fig. 1k), and no fungal proliferation was observed in the phloem or pith in V. fordii (Fig. 1j, l). In contrast, Fof-1 failed to invade the xylem of the lateral roots horizontally (Fig. $1^{\circ}$ ), and the pathogen could not move upwards through the phloem or pith in resistant $V$. montana (Fig. 1n, p). At $11 \mathrm{dpi}$, the fungi had spread to the stem xylem and caused wilting symptoms in susceptible $V$. fordii (Fig. 1a, m), while Fof-1 could still not infect the root xylem in resistant $V$. montana (Fig. 1q).

\section{$V m D 6 P K L 2$ transcript and protein specifically expressed in the root xylem of resistant $V$. montana}

The full-length sequences of VfD6PKL2 and VmD6PKL2 were amplified from $V$. fordii and $V$. montana, respectively. Both the VfD6PKL2 and VmD6PKL2 genes contained $1833 \mathrm{bp}$ of coding sequence (CDS) and encoded a 610 -amino-acid protein with a predicted molecular mass of $67.1 \mathrm{kDa}$ (Fig. S3a). The D6PKL2 gene was a member of the PKC-like superfamily, with good local hydrophilicity but a lack of signal peptides and transmembrane helices (Fig. S3c-f). The active regions of proteins were concentrated mainly in 214-572 aa. Residue 442 within the conserved domain and seven other amino acids outside the conserved region were different in the two species (Fig. S3a, c). In terms of the gene structure, D6PKL2 genes contained two introns in both $V$. fordii and $V$. montana 


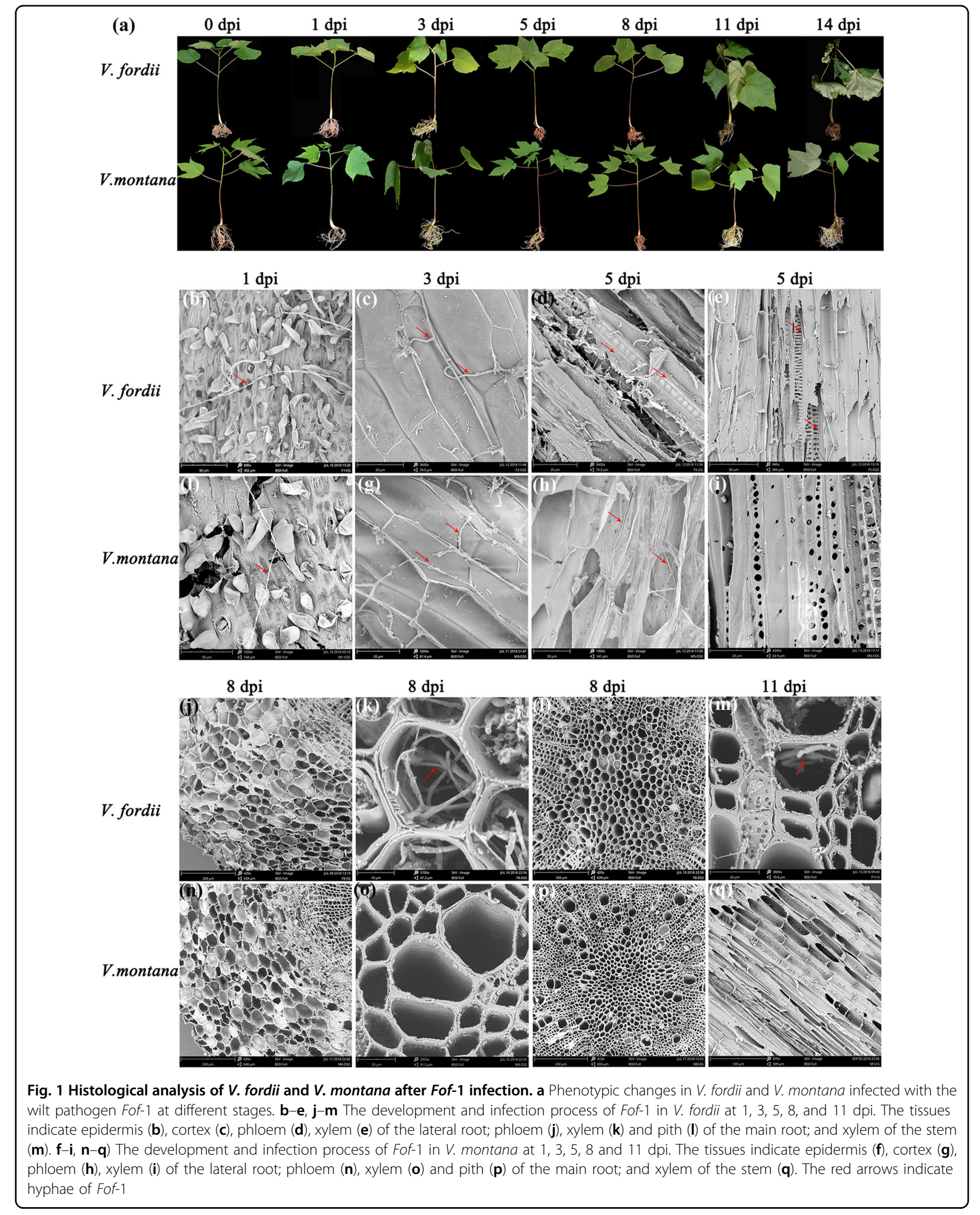


(a)

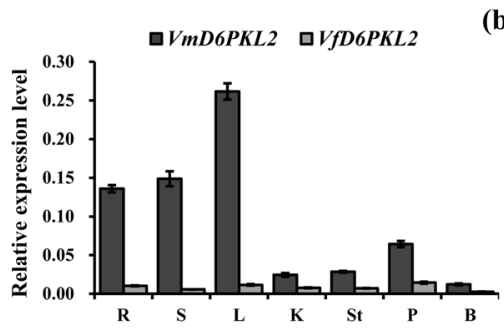

(b)

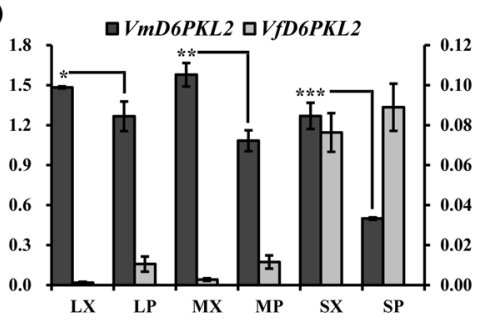

(d)

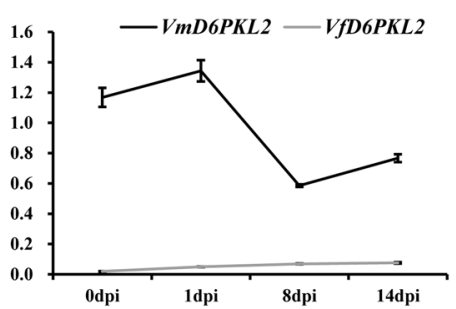

(c)

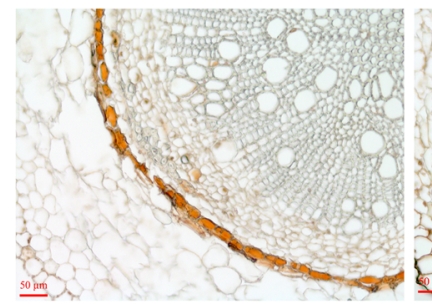

V. montana_Control

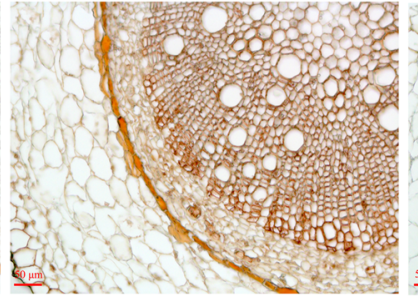

V. montana_Immunization

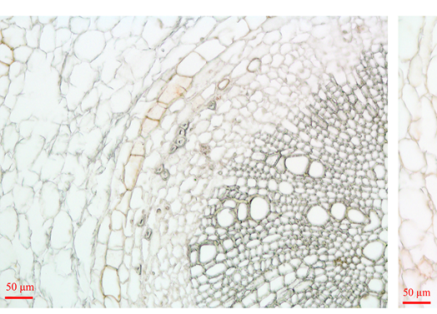

V.fordii_Control

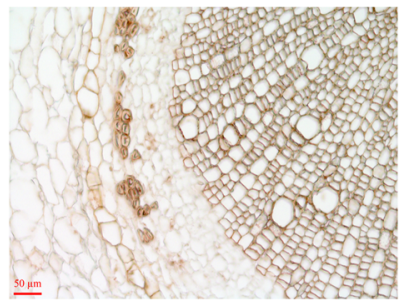

V.fordii_Immunization

Fig. 2 Expression pattern and immunolocalization analysis of VfD6PKL2 and VmD6PKL2. a Tissue-specific expression patterns of VfD6PKL2 and VmD6PKL2 in root (R), stem (S), leaf (L), kernel (K), stamen (St), petal (P) and bud tissues (B). The $y$-axis indicates the relative expression level analyzed using qRT-PCR in triplicate. $\mathbf{b}$ Tissue-specific expression patterns of VfD6PKL2 and VmD6PKL2 in xylem of lateral root (LX), phloem of lateral root (LP), xylem of main root (MX), phloem of main root (MP), xylem of stem (SX), and phloem of stem (SP). The primary and secondary $y$-axes indicate the relative expression levels of VmD6PKL2 and VFD6PKL2, respectively. Significant differences were determined by ANOVA and are represented with asterisks $\left({ }^{*} P<0.05,{ }^{* *} P<0.01\right.$ and $\left.{ }^{* *} P<0.001\right)$. c Immunolocalization analysis of D6PKL2 in the main root of $V$. montana and $V$. fordii. Bars, $50 \mu m$. d Expression trends of VFD6PKL2 and VmD6PKL2 in response to Fof-1 at four infection stages

(Fig. S3b). One intron lay in the $5^{\prime}$ untranslated regions (UTRs), and the other lay in the coding region. Sequencing of root tissues at four infection stages $(0,1,8,14 \mathrm{dpi})$ revealed no alternative splicing of VfD6PKL2 or $V m D 6 P K L 2$ in response to Fof-1 infection (Fig. S3g).

The tissue-specific expression patterns between the orthologous VfD6PKL2 and VmD6PKL2 were compared in seven tissues, including root, stem, leaf, kernel, stamen, petal and bud tissues (Fig. 2a). In general, the transcript abundance of VmD6PKL2 was higher than the transcription abundance of VfD6PKL2 in the seven tissues. The gene expression of $V m D 6 P K L 2$ in vascular tissues, such as roots, stems and leaves, was much higher than the gene expression of VmD6PKL2 in nonvascular tissues. On this basis, we further investigated the expression levels of VfD6PKL2 and $V m D 6 P K L 2$ in the xylem and phloem of lateral root, main root and stem tissues (Fig. 2b). The transcript abundance of $V m D 6 P K L 2$ in xylem was significantly higher than the transcript abundance in phloem in all of the vascular tissues examined. In contrast, the expression of VfD6PKL2 in xylem was significantly lower than the expression of VfD6PKL2 in phloem $(P<0.05)$. To detect the expression of D6PKL2 at the protein level, a qualified antiD6PKL2 antibody was prepared by which VmD6PKL2 can be specifically detected from root total protein (Fig. S4a, b). Immunolocalization analysis further revealed that VmD6PKL2 exhibited specifically higher expression levels in xylem in resistant $V$. montana at the protein level (Fig. 2c).

\section{$V m D 6 P K L 2$ as a novel resistance gene to Fof-1 in the root xylem of $V$. montana}

To further explore the expression mode between VfD6PKL2 and VmD6PKL2 in response to the Fof-1 pathogen, expression patterns in root tissues at $0,1,8$, and 14 dpi were investigated (Fig. 2d). We revealed that $V f D 6 P K L 2$ and $V m D 6 P K L 2$ displayed different expression patterns in response to Fof-1 infection. VfD6PKL2 maintained a steady and significantly lower expression level than VmD6PKL2 during pathogen infection. VmD6PKL2 exhibited an increased expression pattern at the first infection stages at the transcript level. Western blot analysis further revealed that VmD6PKL2 was induced in response to Fof-1 infection (Fig. S4c).

Arabidopsis was used to identify whether D6PKL2 was involved in the defense against Fof-1. First, the transcript abundance of D6PKL2 in wild-type before and after infection was detected, and the results revealed that infection with $F o f-1$ significantly induced the expression of D6PKL2 (Fig. 3a). Then, the homozygous null mutant lines of $d 6 p k l 2-1$ and $d 6 p k l 2-3$ (Figs. S5a, 3b) as well as the wild-type were used to examine whether $d 6 p k l 2$ mutants displayed enhanced susceptibility to fungal pathogens. After infection with $F o f-1$ for approximately seven days, the $d 6 p k l 2$ mutant plants showed more severe yellowing symptoms and displayed significantly higher diseased leaf area than the wild-type plants (Fig. 3c, f). 

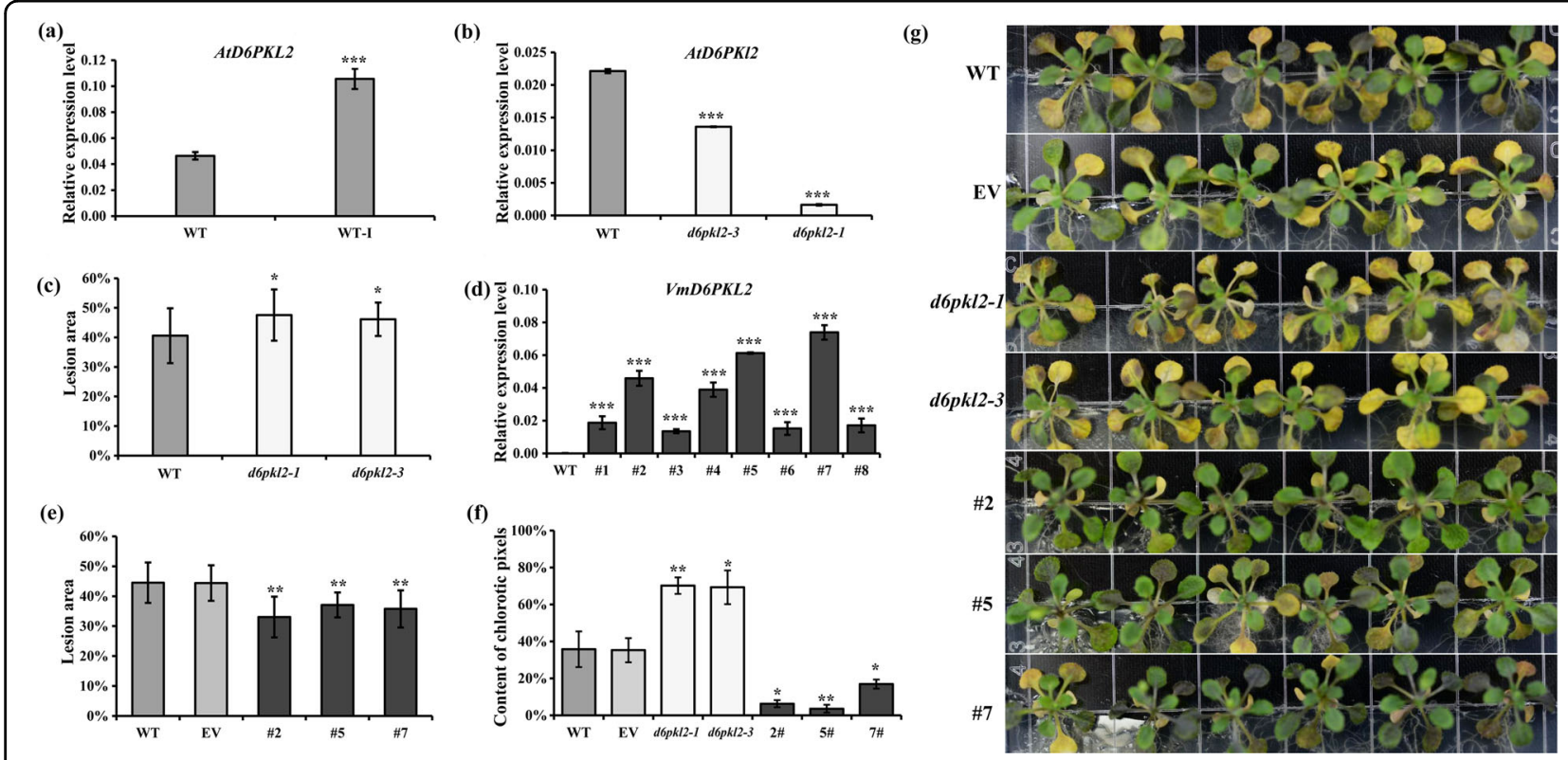

Fig. 3 Resistance ability analysis of mutant and transgenic Arabidopsis overexpressing VmD6PKL2 in response to Fof-1. a Changes in the relative expression levels of AtD6PKL2 in wild-type Arabidopsis after Fof-1 infection. WT-I indicates plants infected with Fof-1 at 7 dpi. Relative expression levels of AtD6PKL2 (b) and diseased leaf area at $7 \mathrm{dpi}$ (c) of wild-type and homozygous mutants. The lesion area indicates the disease severity and was calculated based on the ratio of leaves showing disease symptoms using the open-source software Image ${ }^{55}$. $\mathbf{d}$ Relative expression levels of VmD6PKL2 in wild-type and eight transgenic lines (35S:VmD6PKL2-GFP). e Diseased leaf area of control plants (wild-type and empty vector) and the three selected transgenic lines at $7 \mathrm{dpi}$. $\mathbf{f}$ The content of chlorotic pixels of wild-type (WT), empty vector (EV), mutant lines (d6pkl2-1, d6pk/2-3), and VmD6PKL2-overexpressing transgenic lines (\#2, \#5, \#7) infected with Fof-1 at 7 dpi. The analysis was conducted with reference to Pavicic et al. ${ }^{56}$. $\mathbf{g}$ Disease symptoms of mutant lines (d6pk12-1, d6pk/2-3) and WT, EV, and VmD6PKL2-overexpressing transgenic lines (\#2, \#5, \#7) infected with Fof-1 at $7 \mathrm{dpi}$. Three independent infection experiments were carried out with at least 24 plants per genotype in each experiment. Error bars represent \pm SD. Significant differences were determined by ANOVA and are represented with asterisks $\left({ }^{*} P<0.05,{ }^{* *} P<0.01\right.$ and $\left.{ }^{* * *} P<0.001\right)$

To verify that VmD6PKL2 played an essential role in resistance to Fof-1, the coding sequence of VmD6PKL2 was overexpressed in wild-type Arabidopsis under the control of the CaMV35S promoter. Arabidopsis containing the empty vector was used as the control. The transgenic lines with obvious phenotypic defects due to ectopic expression were removed. Compared with the wild-type, eight T3 transgenic lines displayed significantly higher transcript abundance of $V m D 6 P K L 2$. Lines \#2, \#5, and \#7 with the highest expression levels were chosen for further study (Fig. 3d). In all three positive transgenic lines, green fluorescence was well expressed in the root tips (Fig. S5b). The lateral roots of the transgenic lines formed early and were better developed, and the growth rate was slightly faster than the growth rate of the wild-type plants. Upon pathogen infection, leaf chlorosis, yellowing and necrosis were evident in the control plants (wild-type and empty vector), whereas the VmD6PKL2 transgenic lines exhibited a significantly reduced percentage of diseased leaf area and much milder symptoms (Fig. 3e, f). Taken together, these results imply that transgenic Arabidopsis overexpression of $V m D 6 P K L 2$ displayed enhanced resistance against Fof-1 infection.

To further verify the resistance ability of VmD6PKL2, we performed genetic transformation of $V m D 6 P K L 2$ in
Ailsa Craig tomato plants. Positive transgenic tomato plants were identified using specific primers for $V m D 6 P K L 2$ (Fig. S6). Then, the transgenic tomatoes were further inoculated with $F$. oxysporum f. sp. Lycopersici $(F o l)$. The $F o l$ infection experiment results showed that the wild-type tomatoes infected with $\mathrm{Fol}$ had yellow leaves and wilting disease symptoms at $17 \mathrm{dpi}$, while the transgenic tomato lines grew well, and no wilt symptoms were observed after Fol infection (Fig. 4). These results indicated that the resistance ability was significantly increased in the transgenic tomatoes expressing VmD6PKL2 compared with the wild-type tomatoes.

\section{VmD6PKL2 interacts with VmSYT3}

To explore the interacting protein with VmD6PKL2, a yeast two-hybrid screen based on the infected root tissues in $V$. montana was performed. The $100 \%$ recombinant frequency and CFU greater than $7.6 \times 10^{6}$ revealed that the uncut and second cDNA libraries were constructed successfully (Fig. S7a, b). The further constructed yeast library exhibited $3 \times 10^{7}$ cells $/ \mathrm{m}$ library titer and $95 \%$ recombinant frequency, which met the requirements of library construction (Fig. 5a). The self-activation ability analysis suggested that VmD6PKL2 was transformed into 


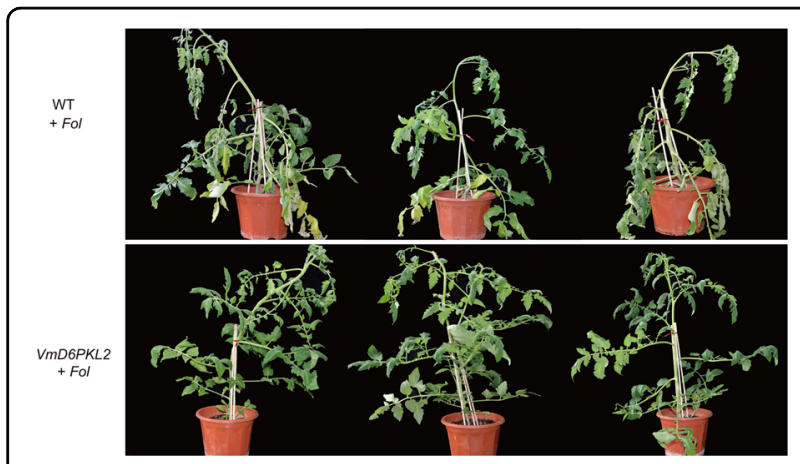

Fig. 4 Resistance ability analysis of transgenic tomato lines overexpressing VmD6PKL2 in response to pathogen Fol. WT + Fol represents wild-type tomato plants infected with pathogen Fol. $V m D 6 P K L 2+F o l$ indicates that transgenic tomato lines overexpressing VmD6PKL2 were infected with Fol. The symptoms of plants after infection with Fol were observed at $17 \mathrm{dpi}$

the yeast strain successfully but could not activate the reporter gene by itself (Fig. S7c).

For bait-and-prey yeast-mating analysis, 32 colonies grown on triple synthetic dropout nutrient screening medium with blue color were identified as components that potentially interacted with VmD6PKL2. In addition, 20 out of the 32 colonies grew and turned blue on the quadruple SD nutrient screening medium (Fig. S7d). Finally, one-to-one cotransformation screening and sequencing analysis verified that five nonredundant candidate proteins, synaptotagmins 3 (SYT3), BREVIS RADIX-LIKE 4 (BRXL4), glucose-6-phosphate dehydrogenase 6 (G6PD6), ATP-binding cassette I15 (ABCI15), and hypersensitive to latrunculin B1 (HLB1), exhibited potential interactions with VmD6PKL2 in $V$. montana (Fig. 5b). The annotation, classification, and potential functions of these five genes are displayed in Table 1.

\section{VmD6PKL2 directly captures VmSYT3 in vitro}

The direct interactions between VmD6PKL2 and VmSYT3 or VmBRXL4 were confirmed by GST pulldown assays in vitro. First, the ORF sequences of the $V m S Y T 3$ gene encoding a 538-amino-acid protein and the $V m B R X L 4$ gene encoding a 377-amino-acid protein were amplified to construct recombinant plasmids PGEX-GSTVmSYT3 and PGEX-GST-VmBRXL4. The prediction of transmembrane helices revealed that the seventh to $29^{\text {th }}$ amino acids of VmSYT3 made up the transmembrane region (Fig. S7e). We therefore truncated the amino acids and selected the region of 50 aa to 538 aa to fuse with GST and express recombinant protein (Fig. S8a). SDSPAGE and immunoblotting with antiGST antibody showed that GST tags could be detected in the purified GST-VmSYT3 and GST-VmBRXL4 proteins as well as GST protein (Fig. S8b, c). The molecular mass of GST-
VmBRXL4 was approximately $70 \mathrm{kDa}$, and GST-VmSYT3 was approximately $81 \mathrm{kDa}$, which was consistent with the target protein (Fig. S8c).

GST-VmSYT3 or GST-VmBRXL4 fusion protein bound to glutathione-coated beads was further assayed for the ability to pull down VmD6PKL2. As displayed in Fig. 5c, GST-VmSYT3 protein and GST protein were detected by antiGST antibody, suggesting that these two proteins bound to Sepharose beads successfully. Immunoblot analyses using an antiD6PKL2 antibody also demonstrated that VmD6PKL2 was pulled down by GSTVmSYT3 but not by GST. Similarly, Western blot assay detected the existence of GST and GST-VmBRXL4 and verified that VmD6PKL2 could be pulled down only by GST-VmBRXL4 in Fig. 5c, indicating that GSTVmBRXL4 binds to VmD6PKL2 in vitro. All these results revealed that VmD6PKL2 can directly interact with VmSYT3 or VmBRXL4.

\section{VmD6PKL2 suppresses VmSYT3-mediated negative regulation}

To identify whether SYT3 was involved in the defense against Fof-1, tissue-specific expression patterns of both VFSYT3 and VmSYT3 in vascular tissues were investigated. Similar to the expression modes of $V f / V m D 6 P K L 2$, $V m S Y T 3$ was specifically expressed in the xylem, while VFSYT3 showed almost no expression in any of the vascular tissues (Fig. 6a). In addition, after infection with Fof1 , the transcript abundance of $V m S Y T 3$ was gradually downregulated, whereas little change was displayed in the expression of VfSYT3 (Fig. 6b). This result suggested that the root xylem-specifically expressed $V m S Y T 3$ may act as a negative regulator of wilt disease.

Wild-type Arabidopsis and syt3 mutants were used to detect the resistance ability against Fof -1 . Homozygosity verification showed that all of the syt3-2 and several syt3-3 mutant lines were homozygous, but all syt3-1 were heterozygous (Fig. S9a, b). In addition, qRT-PCR analysis revealed that syt3-2 but not syt3-3 displayed significantly lower expression levels than the wild-type (Fig. S9c). Therefore, homozygous syt3-2 mutants were selected for further investigation. Inoculation results indicated that the syt3-2 mutant lines showed significantly lower diseased leaf area and lighter wilting disease symptoms than the wild-type plants (Fig. 6c, f), suggesting that SYT3 negatively regulates defense responses.

To examine the regulation of SYT3 by VmD6PKL2, we detected the transcript abundance of AtSYT3 in $d 6 p k l 2$ mutants and transgenic Arabidopsis overexpressing $V m D 6 P K L 2$. The results revealed that the mutation of AtD6PKL2 increased the expression level of AtSYT3 (Fig. 6d), and, in contrast, AtSYT3 was significantly downregulated in all three transgenic Arabidopsis lines overexpressing VmD6PKL2 (Fig. 6e). 
(a)

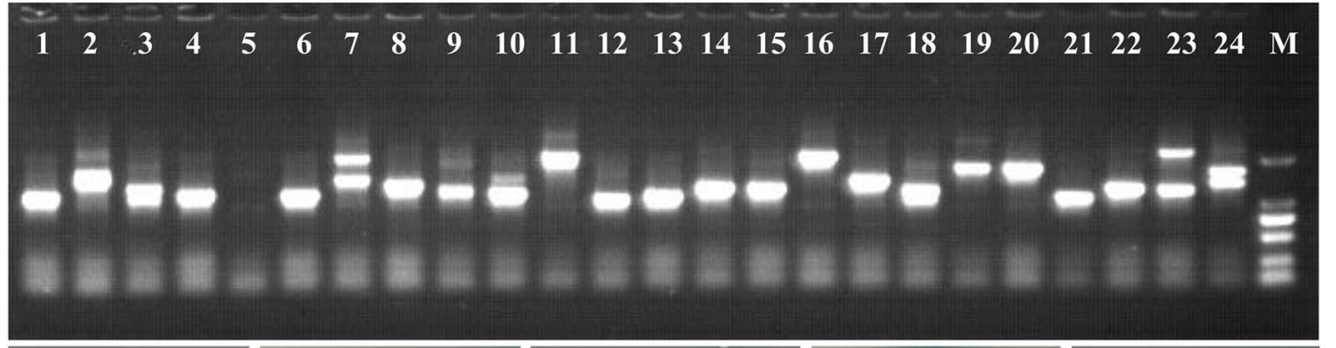

(b)

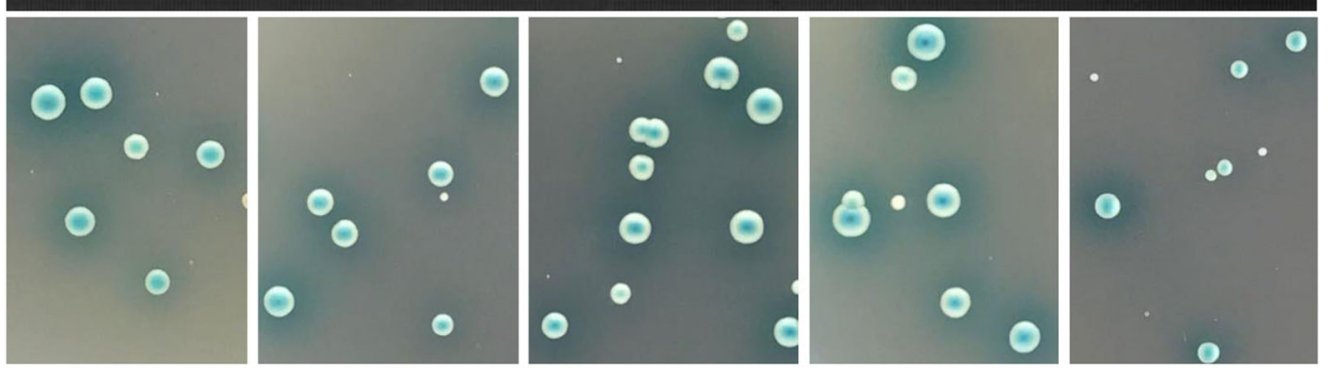

(c)
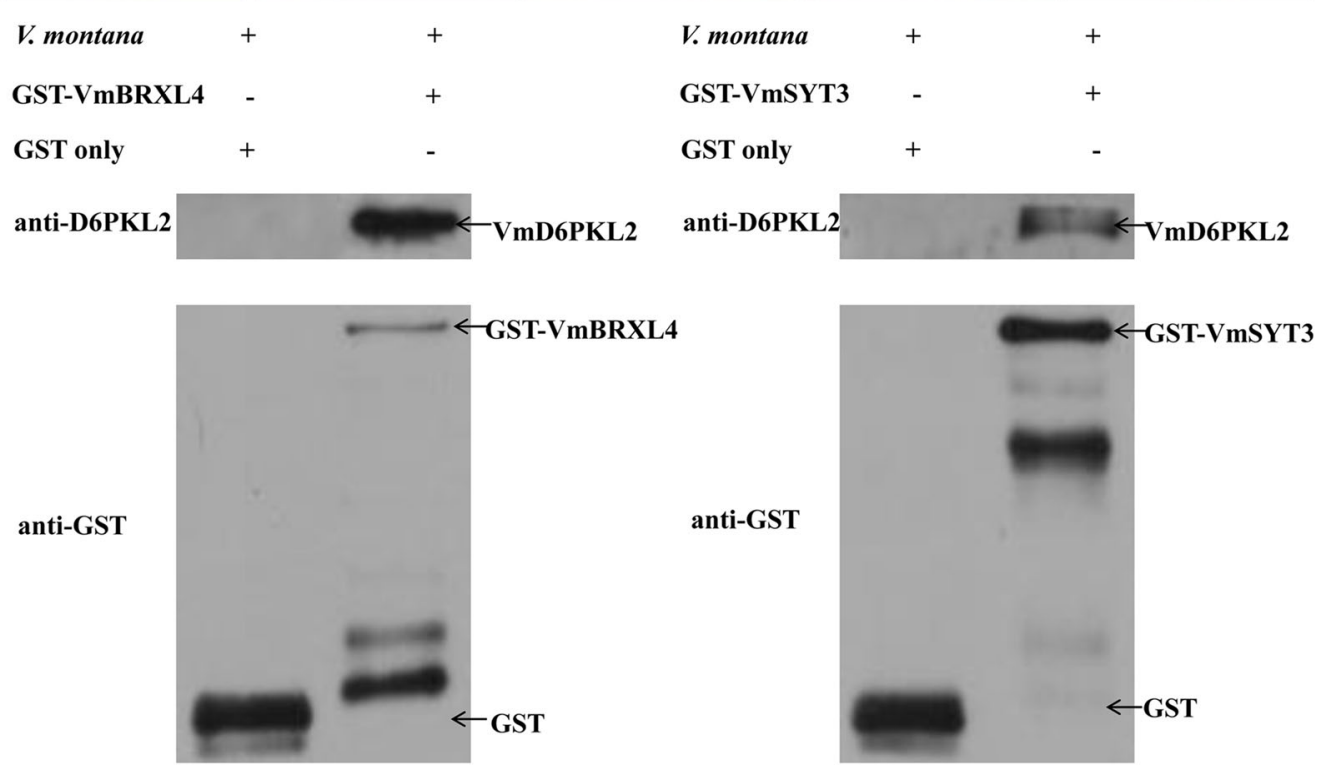

Fig. 5 Yeast two-hybrid analysis of VmD6PKL2. a Calculation of recombination frequency and length of inserted fragments of yeast cDNA library. Lanes 1-24 represent the 24 randomly selected colonies, and M represents the DL2000 DNA marker. $\mathbf{b}$ The five nonredundant positive interaction proteins identified by one-to-one-interaction screening and sequencing analysis. From left to right: VmBRXL4, VmSYT3, VmABCI15, VmG6PD6, and VmHLB1. c Detection of the direct interaction between VmD6PKL2 and VmBRXL4 (left) or VmSYT3 (right). Plus and minus symbols indicate added and omitted components, respectively. The proteins detected by the antiGST or antiD6PKL2 antibody are indicated with arrows

\section{Discussion}

Although numerous studies on plant Fusarium wilt disease have been performed ${ }^{5,17}$, the detailed process of root infection by the pathogenic $F$. oxysporum and the genetic basis for resistance or susceptibility of plants to wilt diseases remain obscure. In this study, the divergent infection process of $F o f-1$ into susceptible $V$. fordii and resistant $V$. montana were presented, respectively (Fig. 1). This is the first known report detailing the systemic infection process of $F$. oxysporum within trees. Infections took place through the secondary roots but not the main root, which was consistent with the finding by Trujillo, Snyder ${ }^{18}$. Subsequently, after penetrating the epidermis of lateral roots, Fof-1 grew centripetally and infected the cortex, phloem and xylem in V. fordii (Fig. 1). Colonization in xylem vessels is a crucial step of the infection process for the vascular wilt disease pathogen. From this stage on, the fungi were confined to the xylem vessels and moved upwards to the main root. Sporulation and germination of secondary mycelium are considered crucial for rapid upward colonization ${ }^{9}$. The microconidia, carried upwards by the xylem stream, were observed prior to 
Table 1 Annotation and function of proteins interacting with VmD6PKL2

\begin{tabular}{|c|c|c|}
\hline Name & Family & Function \\
\hline SYT3 & $\begin{array}{l}\text { Calcium-dependent lipid-binding (CaLB domain) } \\
\text { family protein }\end{array}$ & $\begin{array}{l}\text { A paralog of SYT1 is involved in fungi defense }{ }^{37} \text {; the putative calcium sensor catalyze } \\
\mathrm{Ca}^{2+} \text {-triggered vesicles fusion }{ }^{51} \text {. }\end{array}$ \\
\hline BRXL4 & BRX gene superfamily & $\begin{array}{l}\text { A paralog of BRX acts as a molecular rheostat to modulate auxin efflux dynamically }{ }^{52} \text {; } \\
\text { interact with the pathogens defense gene } R L M 3^{53} \text {. }\end{array}$ \\
\hline G6PD6 & G6PD-C superfamily & Positive resistance gene to bacterial pathogen and root-knot nematode ${ }^{42,43}$ \\
\hline $\mathrm{ABCl15}$ & ABC transporter family & $\begin{array}{l}\text { Lipidic metabolic intermediates transport; some } A B C \text { transporters involved in pathogen } \\
\text { resistance }{ }^{46} \text {. }\end{array}$ \\
\hline HLB1 & Tetratricopeptide repeat (TPR)-like superfamily & Modulate the trans-Golgi network/early endosome (TGN/EE) ${ }^{54}$. \\
\hline
\end{tabular}

(a)

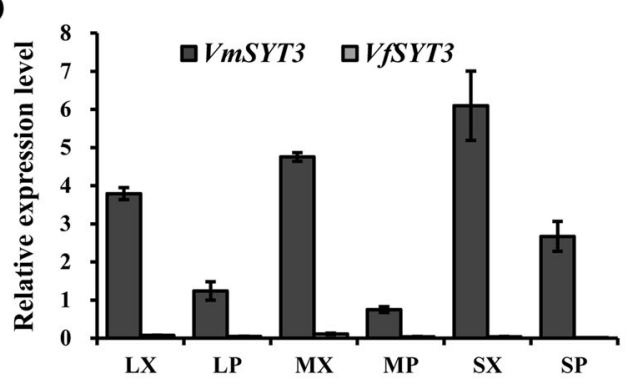

(c)

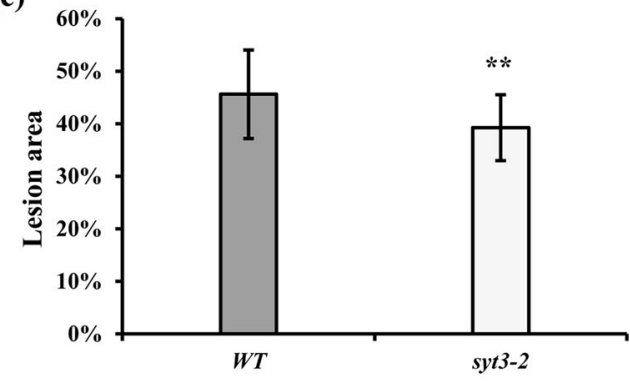

(e)

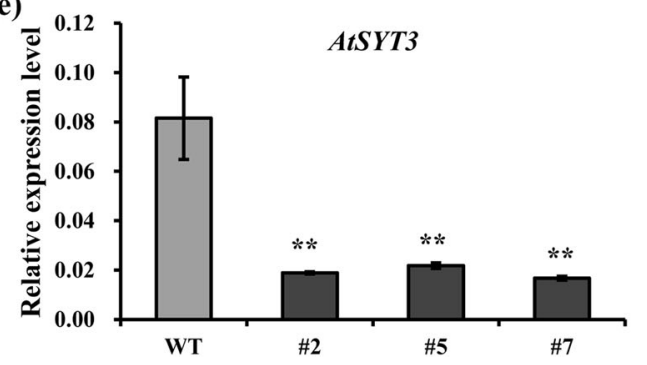

(b)

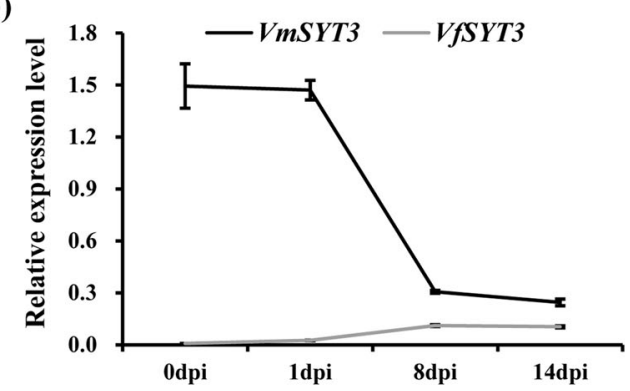

(d)

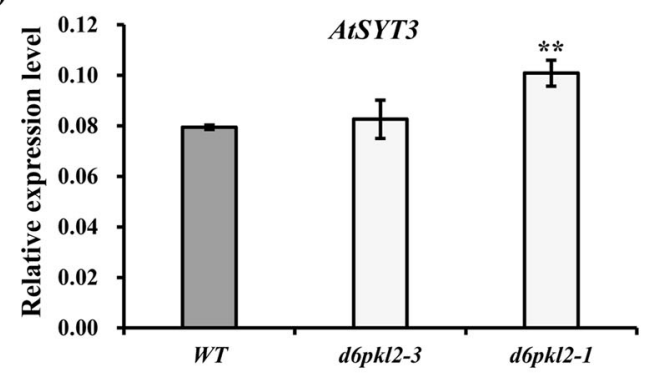

(f)

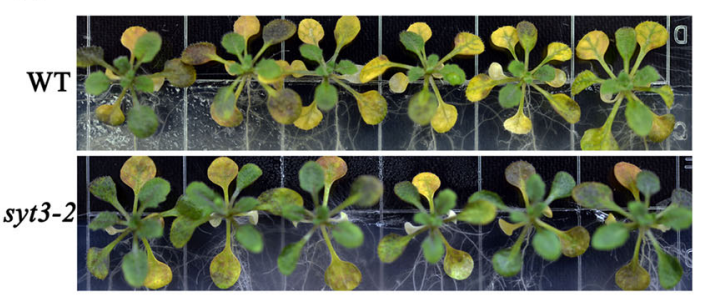

Fig. 6 Resistance ability analysis of syt3 mutants in response to Fof-1 and the regulation of SYT3 by D6PKL2. Three independent infection experiments were performed. Significant differences are indicated with asterisks. a Tissue-specific expression patterns of VfSYT3 and VmSYT3 in Xylem and phloem of vascular tissues. LX, xylem of lateral root; LP, phloem of lateral root; MX, xylem of main root; MP, phloem of main root; SX, xylem of stem; SP, phloem of stem. $\mathbf{b}$ Expression trends of VFSYT3 and VISYT3 in response to Fof-1 at four infection stages. Diseased leaf area (c) and disease symptoms (f) of the syt3-2 mutant and wild-type infected with Fof-1 at 7 dpi. Changes in the relative expression levels of AtSYT3 in d6pkl2 mutants (d) or transgenic Arabidopsis overexpressing VmD6PKL2 (e) compared with wild-type Arabidopsis. Significant differences were determined by ANOVA and are represented with asterisks $\left({ }^{*} P<0.01\right)$ 
mycelium infection in the xylem of the stem (Fig. 1). In $V$. fordii, chlamydospores were produced on the lateral or terminal of the hyphae as they invaded the xylem of the lateral root (Fig. S2d, h). Interestingly, chlamydospores were generated only when the fungi enter the xylem in all early infection processes, contrary to the common assumption that they are produced only after the death of the plant ${ }^{19}$. The wilt disease development of branches and leaves was significantly correlated with the infection site of roots, consistent with the mode of pathogen expansion observed in the field. In detail, if the fungi only infected the lateral roots on one side of the tree, the main root in that direction was infected; accordingly, the vascular bundles of the trunk, branches and leaves in that position became necrotic and wilted. If half of the lateral roots and main root were infected, then half of the trunk, branches and leaves were withered from the whole tree.

The initial infection process of Fof-1 in resistant $V$. montana was similar to the initial infection process in susceptible $V$. fordii. In detail, the hyphae can penetrate the epidermis, invade the cortex, and enter the phloem of lateral roots. However, then, fungal propagation appeared to be halted. The hyphae could not spread sequentially to the xylem vessels of lateral roots and main root (Fig. 1). These results indicate that the resistance of $V$. montana to Fusarium wilt disease does not occur at the penetration stage but through inhibiting pathogen progression. In addition, the xylem of the lateral root of $V$. montana, exposed directly to the pathogen, showed almost no fungal infection (Fig. S2g). These results reveal that the resistance of $V$. montana to wilt disease is closely related to xylem, which probably inhibits the invasion of Fof-1.

Inoculation experiments showed that $V$. montana was resistant to Fusarium wilt disease not only under natural conditions but also under growth-chamber conditions. Correspondingly, V. fordii is highly susceptible to Fof-1 under natural and controllable conditions, revealing that genetic factors affect the resistance or susceptibility of plants to fungi to a great extent. Our previous study suggested that VmD6PKL2 may be a hub gene in resistance to Fof-1 in $V$. montana ${ }^{7}$. D6PKL2, together with D6PK, D6PKL1, and D6PKL3, forms the D6PK subfamily within the AGCVIIIa family of Arabidopsis serine/threonine protein kinases ${ }^{20}$. AGC kinases are named after protein kinase A (PKA), cyclic GMP-dependent protein kinases (PKG) and protein kinase C (PKC) ${ }^{21}$. Many AGC kinases, such as protein kinase 1 (OsPdk1), oxidative signal inducible 1 (OXI1), and TaAGC1, have been suggested to defend against pathogens and plant immunity $^{22-25}$. Studies on D6PKL2 and the related D6PKs have focused on the control of auxin transport-dependent growth $^{26}$. Auxin plays important roles in the differentiation of xylem cells, radial pattern formation of vascular bundles and molding plant-pathogen interactions ${ }^{27-29}$. d6pk012 triple mutants are severely impaired in several developmental processes, including tropic responses, lateral root formation and phototropic hypocotyl bending $^{16,30}$. However, to date, it is unknown whether D6PKL2 is involved in disease resistance. The data here indicated that $V m D 6 P K L 2$, rather than VfD6PKL2, was induced in response to fungal infection, and $V m D 6 P K L 2$ transcripts and protein were both specifically expressed in the root xylem (Fig. 2). Furthermore, transgenic Arabidopsis and tomatoes overexpressing VmD6PKL2 exhibited high resistance ability, while the mutant lines were more susceptible to the pathogen (Fig. 3). Interestingly, Arabidopsis atd6pkl2 and overexpression lines exhibited subtle disease phenotypes compared with the overexpression of VmD6PKL2 in tomatoes. Based on our anatomic analysis (Fig. 1), the xylem of the lateral roots is the key position for the resistance ability to Fof- 1 in $V$. montana trees. We therefore suspected that the relatively weak secondary xylem of Arabidopsis, not as strong as the secondary xylem of tung trees and tomatoes, may be the reason for the subtle disease phenotypes.

How is VmD6PKL2 positively involved in lateral root xylem resistance to the pathogen? SYT3, one of five synaptotagmins (SYTs) encoded by Arabidopsis ${ }^{31}$, was identified to directly interact with VmD6PKL2 in resistant V. montana (Fig. 4b, c). Mammalian SYTs act as $\mathrm{Ca}^{2+}$ sensors to trigger synaptic vesicle fusion and hormone secretion $^{32}$. In addition, plant SYTs containing two $\mathrm{C}$-terminal calcium-binding domains $(\mathrm{C} 2 \mathrm{~A}$ and $\mathrm{C} 2 \mathrm{~B})$, such as mammalian Syts, may also act as a calcium sensor ${ }^{33} \cdot \mathrm{Ca}^{2+}$ sensors can sense cytosolic $\mathrm{Ca}^{2+}$ elevations rapidly caused by a variety of stimuli ${ }^{34}$ and give rise to altered gene expression patterns and protein phosphorylation ${ }^{35}$. In addition, calcium signals are crucial in plant defense-signaling pathways ${ }^{35}$ and may trigger protein kinases $^{36}$. These results led us to hypothesize that after Fof-1 infection, VmSYT3 in xylem recognized calcium influx and transmitted the signal to VmD6PKL2 in a $\mathrm{Ca}^{2+}$ -dependent manner, which activated the expression of VmD6PKL2 (Fig. 7). In our study, we further identified that $S Y T 3$, similar to the function of $A t S Y T 1^{37}$, negatively defended against Fusarium wilt disease. In addition, overexpression of VmD6PKL2 significantly downregulated the expression level of SYT3 (Fig. 6). These results suggested that $V m D 6 P K L 2$ activated by VmSYT3 could in turn suppress AtSYT3-mediated negative regulation through posttranscriptional modification.

Phosphorylation is critically important for the regulation of protein function ${ }^{38}$. Many diseases occur as the result of mutated phosphorylation sites ${ }^{39}$. D6PKs are suggested to be key regulators of PIN-FORMED (PIN1) phosphorylation $^{40}$. In our study, some of the other candidate proteins that interact with VmD6PKL2, including G6PD6 and ABCI15, have a known or suspected role in 


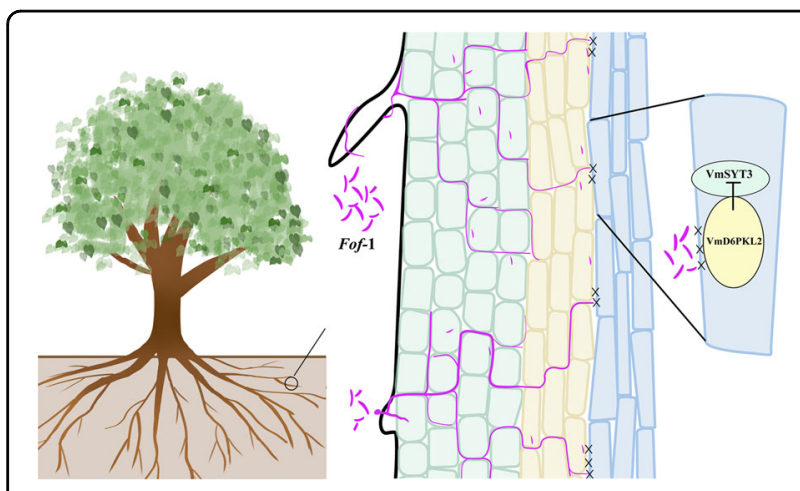

Fig. 7 A proposed model for the infection process of pathogen Fof- 1 and potential defense response of $V$. montana. The microconidia of Fof-1 germinated and colonized the epidermis of the lateral root. After penetration into root hairs, hyphae continue to grow centripetally and infect the cortex and phloem, but further invasion into xylem is blocked. VmD6PKL2 positively regulates resistance against Fusarium wilt disease through suppression of VmSYT3mediated negative regulation

plant defense in a phosphorylation-dependent manner (Table 1). G6PD, a key enzyme of the oxidative pentose phosphate pathway, exhibits pathogen-inducible activity and provides equivalents important for defense respon$\operatorname{ses}^{41}$. Mutation of cytosolic isoform G6PD6 resulted in increased susceptibility of Arabidopsis to the Pseudomonas syringae and root-knot nematode ${ }^{42,43}$. Phosphorylation stimulated the activity of G6PD6, which is critical for plant adaptation to abiotic and biotic stresses ${ }^{44}$. ABC transporters regulate the overall development and stress tolerance of plants via the transport of cellular building blocks and secondary metabolites ${ }^{45,46}$. Many ABC transporters have been identified to confer resistance to multiple fungal pathogens and insects ${ }^{47-49}$. Phosphorylation is constitutive and required for full transporter activity ${ }^{38}$. These results lead us to speculate that, in addition to the suppression of $V m S Y T 3$-mediated negative regulation, $V m D 6 P K L 2$ could positively regulate disease resistance through the activation of downstream defense-related genes in a phosphorylation-dependent manner (Fig. 6).

In conclusion, the susceptible and resistant plant sister species make it possible for us to reveal that Fof- 1 failed to invade into the lateral root xylem of resistant tree species, while it spread upwards through the root xylem in susceptible tree species. This finding reminds us that the lateral root xylem is a key barrier for Fusarium pathogen infection. More importantly, $V m D 6 P K L 2$, specifically expressed in the root xylem and induced in response to Fof- 1 infection, acts as a resistance gene against Fof- 1 by suppressing VmSYT3-mediated negative regulation in the lateral root xylem. This result further illuminates our understanding of the basis of genetic resistance against Fusarium in the root xylem of resistant plant species. The findings provide novel insight into Fusarium wilt resistance in plants.

\section{Materials and methods \\ Plant materials and growth conditions}

Tung trees and Arabidopsis were used in this work. Seeds of $V$. fordii and $V$. montana were harvested in Guangxi Zhuang Autonomous Region, China. They were first immersed in water overnight, sterilized in $0.2 \%$ potassium permanganate for $1 \mathrm{~h}$, and subsequently washed three times in sterile water. The surface-sterilized tung tree seeds were grown in sterile soil under growth-chamber conditions at $26^{\circ} \mathrm{C}$ with a $16 \mathrm{~h}$ light $/ 8 \mathrm{~h}$ dark photoperiod and $60 \%$ relative humidity. The D6PKL2 (At5g47750) and SYT3 (At5g04220) mutants, d6pkl2-1 (SALK_011339C), d6pkl22 (SALK_099935), d6pkl2-3 (SALK_086127), syt3-1 (SALK_005585C), syt3-2 (SALK_124835C), and syt3-3 (SALK_077067), were ordered from the Arabidopsis Biological Resource Center (ABRC).

The three-primer method was used to confirm the homozygous mutants. The primers were designed at the website http://signal.salk.edu/tdnaprimers.2.html. The T-DNA insertion site of the homozygous mutants $d 6 p k l 2-$ 1, d6pkl2-3, and syt3-2 used for infection investigation was exon. Arabidopsis wild-type (WT) Columbia (Col-0) and mutant seeds were surface-sterilized in $75 \%$ ethyl alcohol for $30 \mathrm{~min}$ and germinated on 1/2 Murashige and Skoog (MS) medium containing 1.5\% sucrose and $0.5 \%$ agar under a $16 \mathrm{~h}$ light $/ 8 \mathrm{~h}$ dark cycle and $60 \%-75 \%$ relative humidity at a temperature of $23^{\circ} \mathrm{C}$.

\section{Agrobacterium tumefaciens-mediated transformation of Fof-1}

The Fof-1 pathogen was isolated from infected tung tree plants in Guangxi Zhuang Autonomous Region, $\mathrm{China}^{7}$ and maintained on potato dextrose agar (PDA) at $28^{\circ} \mathrm{C}$. Conidial spores were collected with sterile distilled water and diluted to the desired concentration of $1 \times 10^{6}$ spores per ml. The $A$. tumefaciens strain AGL-1 carrying the plasmid pKD1-GFP was used for the genetic transformation of Fof- 1 . Transformants were selected on PDA containing hygromycin B $\left(100 \mu \mathrm{g} \mathrm{ml}^{-1}\right)$. The expression of GFP and the hygromycin B phosphotransferase gene ( $h p h)$ of transformants were further detected by PCR amplification. Meanwhile, the fluorescence expression of the mycelium and conidium of transformants was assessed by a Zeiss LSM700 confocal laser scanning microscope (Carl Zeiss Inc., Jena, Germany). GFP fluorescence was excited at $488 \mathrm{~nm}$ lasers and detected at $500-530 \mathrm{~nm}$. After five subcultures on PDA plates without hygromycin $\mathrm{B}$, transformants were reinoculated on PDA containing hygromycin $\mathrm{B}$ to detect their fluorescence stability. Eventually, the transformants that exhibited high expression of GFP and equal phenotype and pathogenicity with wild-type were selected for pathogen infection assays. 


\section{Fungal infection assays of tung trees and histological analysis}

Seedling plantlets of two-month-old $V$. fordii and $V$. montana with 4-5 leaves were used. The sterile roots of chosen plantlets were drilled with a needle and then placed into the conidial suspension $\left(10^{6}\right.$ spores per $\left.\mathrm{ml}\right)$ for $30 \mathrm{~min}$, while control plants were dipped in sterile distilled water. After inoculation, the plants were replanted in the growth room with $85 \%$ humidity.

The root tip, lateral root without secondary structure, main root with secondary structure, stem and leaf tissues at $0,1-, 3-, 5-, 8-, 11-$, and 14-days post-infection (dpi) were sampled to observe the different infection processes of Fof-1 in $V$. fordii and $V$. montana. Four inoculated plants and three uninfected plants were harvested at each sampling time. For confocal laser scanning microscopy (CLSM) analysis, samples were hand-sectioned into approximately 1-mm-thick slices. Confocal images were acquired on a Zeiss LSM700 confocal laser scanning microscope as described above. Endogenous plant autofluorescence was recorded from 530 to $690 \mathrm{~nm}$.

For scanning electron microscopy (SEM) analysis, vacuumed sections were fixed in $2.5 \%$ glutaraldehyde overnight at $4{ }^{\circ} \mathrm{C}$. Samples were rinsed with PBS three times and then dehydrated in a graded ethanol series $(30,50,70,80,90,95$, and $100 \%)$ for $15 \mathrm{~min}$ per gradient. Afterwards, samples were freeze-dried using a $\mathrm{CO}_{2}$ critical point dryer (Quorum, London, UK) and coated with gold-palladium using a gold spraying instrument (Zhongke Keyi, Beijing, China). Finally, the characteristics of the sample tissues were observed, and electron microphotographs were obtained using a scanning electron microscope (Phenom-world, Eindhoven, Netherlands).

\section{RNA extraction and qRT-PCR analysis}

A series of tissues from tung trees and Arabidopsis was harvested and ground in liquid nitrogen immediately. Among these tissues, root, stem, leaf, kernel, stamen, pistil and bud tissues, as well as xylem or phloem of main root, lateral root and stem in uninfected $V$. fordii and $V$. montana were used for tissue-specific expression analysis. The roots of control and inoculated tung trees at 1, 8, and 14 dpi were used for expression trend analysis. Total RNA extraction and quality detection and first-strand cDNA synthesis were performed according to Zhang (2016). qRT-PCR analysis was used to examine the relative expression levels ${ }^{6}$. AtUBQ5 and EF1a genes from Arabidopsis and tung tree, respectively, were used as internal controls. Three independent biological replicates from each sample were used and analyzed in technical triplicates. The $2^{-\Delta \Delta C T}$ calculation method was used to determine the relative expression levels. Primers were designed using Primer Premier 5.0 (Premier Biosoft, Palo Alto, CA, USA).

\section{Gene isolation and sequence analysis}

The full-length ORF sequences of the VfD6PKL2 and $V m D 6 P K L 2$ genes were amplified from cDNA templates of roots in $V$. fordii and $V$. montana, respectively. Purified sequences were cloned into the pMD18-T vector and transferred into $E$. coli DH5 $\alpha$. The inserted gene fragment of positive transformants was confirmed by sequencing and further BLASTX analysis on NCBI (http://www.ncbi. nlm.nih.gov/). In addition, the Conserved Domain Database (https://www.ncbi.nlm.nih.gov/cdd/), SignalP 4.1 Server (http://www.cbs.dtu.dk/services/SignalP/), TMH MM (http://www.cbs.dtu.dk/services/TMHMM/), and HMMTOP 2.0 (http://www.enzim.hu/hmmtop/html/ submit.html) were used to analyze the encoded amino acid sequences. The sequences of VfD6PKL2 and $V m D 6 P K L 2$ of tung trees infected with Fof- 1 at $0,1,8$, and 14 dpi were used for alternative splicing analysis. Genomic DNA of $V$. fordii and $V$. montana was extracted using a CTAB Plant DNA kit (Aidlab Biotech, Beijing, China). The intron fragments of VfD6PKL2 and VmD6PKL2 were amplified via PCR and then sequenced as described above.

\section{Antibody preparation, Western blotting and immunolocalization}

An antiD6PKL2 polyclonal antibody was developed specifically against the C-terminal peptide antigen APDKKGSDNY (amino acids 595 to 604) of D6PKL2. In detail, the specific peptide sequence was synthesized and detected by HPLC. In addition, the peptide coupled with the immunoenhancer vector via cysteine was used to immunize rabbits. The specificity and titer of VmD6PKL2 antiserum were confirmed by ELISA. Total proteins were extracted from the root tissue of $V$. montana according to the instructions of YeastBuster ${ }^{\mathrm{TM}}$ Protein Extraction Reagent (Merck, Darmstadt, Germany). To validate the specificity of the antiD6PKL2 antibody, total proteins were stained by Coomassie blue after SDS-PAGE, and VmD6PKL2 was detected by antiD6PKL2 antibody in Western blotting analysis. $\beta$-Tubulin was used as internal control.

The lateral roots and main roots of $V$. fordii and $V$. montana were cut into $2-3 \mathrm{~mm}$ pieces and immediately fixed in FAA (50\% ethyl alcohol, 10\% formaldehyde, 10\% glycerol, and $5 \%$ acetic acid) for at least $24 \mathrm{~h}$. After gradual dehydration in gradient concentrations of tert-butanol and ethanol solutions, samples were kept in paraffin at $60{ }^{\circ} \mathrm{C}$ for $48 \mathrm{~h}$. The embedded tissues were further sliced into $12-\mu \mathrm{m}$-thick sections. After dewaxing with xylene, the sections were rehydrated in gradient ethanol and 0.1 M PBS. The blocked slides were inoculated overnight in 1:500 diluted antiD6PKL2 antibodies at $4{ }^{\circ} \mathrm{C}$ and then inoculated in 1:50 diluted HRP-labeled goat antirabbit IgG (Beyotime Biotechnology, Shanghai, China) for $2 \mathrm{~h}$. Finally, the rinsed slides were stained with a DAB 
horseradish peroxidase color development kit (Beyotime Biotechnology, Shanghai, China) for $15 \mathrm{~min}$ and observed under a Leica DM4000B light microscope (Leica, Wetzlar, Germany).

\section{Fungal infection assays of mutant and transgenic Arabidopsis}

The coding sequence of VmD6PKL2 (without the stop codon) was linked to the linear vector pCambia1300-GFP/ $\mathrm{C}$ using Trelief ${ }^{\mathrm{rm}}$ SoSoo Cloning Kit (TSINGKE, Beijing, China). The successfully constructed vector was transformed into Arabidopsis wild-type Col-0 mediated by A. tumefaciens GV3101 using the floral dip method ${ }^{50}$. The harvested Arabidopsis seeds were screened on 1/2MS medium with $20 \mu \mathrm{g} \cdot \mathrm{ml}^{-1}$ hygromycin B. The positive transgenic lines (35 S:VmD6PKL2-GFP) were further confirmed by PCR analysis of VmD6PKL2 and GFP. All the positive transformants were cultivated to the T3 generation, and the expression of VmD6PKL2 in transgenic Arabidopsis was analyzed using qRT-PCR. Subsequently, three independent transgenic lines with higher $V m D 6 P K L 2$ expression levels were selected for fungal infection. Transgenic lines harboring the empty vector (35 S:GFP) were also obtained and used as controls.

The seedlings of WT, transgenic lines (35 S:GFP and 35 $S: V m D 6 P K L 2-G F P), d 6 p k l 2$ and syt 3 mutants grown on $1 /$ 2 MS medium for 7 days were transferred to square dishes containing the same medium. After five days of growth, each Arabidopsis plant was inoculated with a piece of $F$. oxysporum $\mathrm{f}$. sp. fordiis (Fof-1) with the diameter of $5 \mathrm{~mm}$. Three independent experiments were performed with at least 24 plants per genotype in each experiment. Disease progression and chlorosis development were observed and recorded. Disease severity was assessed based on the ratio of yellow leaves to the number of total leaves per plant. Statistically significant differences among independent genotypes were estimated by one-way analysis of variance (ANOVA). Plants were sampled at 0 and $7 \mathrm{dpi}$ for the measurement of the change in expression.

\section{Infection assays of transgenic tomatoes with VmD6PKL2}

The CDS of VmD6PKL2-GFP was inserted into the pCAMBIA1300 vector under the control of the Camv35S promoter. The Ailsa Craig tomato variety was used for genetic transformation, and transformation was conducted using the $A$. tumefaciens-mediated leaf disc method. Transgenic tomato plants (35S:VmD6PKL2-GFP) were further screened using hygromycin $B$ and finally identified using specific primers for hygromycin and VmD6PKL2 (Table S1) using PCR. The transgenic and wild-type seedlings were grown on 1/2 MS medium for 7 days and then transferred to sterile soil for cultivation for approximately two weeks. The roots of wild-type and transgenic tomatoes were drilled with a needle and then injected with conidial suspension $\left(10^{6}\right.$ spores per $\left.\mathrm{ml}\right)$ of $\mathrm{Fol}$ around the roots. After inoculation, the plants were cultivated under growth-chamber conditions at $26^{\circ} \mathrm{C}$ with a $16 \mathrm{~h}$ light $/ 8 \mathrm{~h}$ dark photoperiod and $60 \%$ relative humidity. The symptoms after infection were observed and recorded from 0 to $17 \mathrm{dpi}$.

\section{Construction of cDNA library for yeast two-hybrid assay}

Root tissue of $V$. montana after Fof- 1 infection was used for the extraction of total RNA. The mRNAs were isolated and purified from qualified RNA according to the protocol of the Oligotex mRNA Midi Kit (Qiagen, Hilden, Germany). An uncut-type cDNA library was constructed using the CloneMiner II cDNA Library Construction Kit (Invitrogen, Carlsbad, CA, USA). The plasmids of the qualified uncut cDNA library were extracted for recombination with the yeast expression vector pGADT7-DEST. The recombinant vector was transformed into competent E. coli $\mathrm{DH} 10 \mathrm{~B}$ cells by electroporation. Ten microliters of the transformed cell culture was diluted 1:1000, and $50 \mu \mathrm{l}$ of the solution was spread on LB medium with kanamycin. After incubating overnight at $37^{\circ} \mathrm{C}$, colony-forming units (CFU) of the second cDNA library were calculated as follows: colonies $/ 50 \mu \mathrm{l}$ medium $\times 1000$ times $\times 10^{3} \mu \mathrm{l} \times$ total volume of the library $(\mathrm{ml})$. Twenty-four randomly selected colonies were examined for calculation of recombination frequency and length of inserted fragments by colony PCR amplification. The extracted plasmids of the second cDNA library were subsequently transformed into the competent cells of yeast Y187 with the PEG-LiAc method. After the selection of positive transformants with $\mathrm{SD}$ /-Leu plate medium, the CFU and recombination frequency of the yeast library were calculated.

\section{Yeast two-hybrid screening}

The coding sequence of $V m D 6 P K L 2$ linking EcoR I and $B a m H$ I restriction sites was inserted into the bait-vector PGBKT7. To detect the self-activation ability of VmD6PKL2, PGBKT7-VmD6PKL2 and the positivecontrol combination of PGBKT7-53 and PGADT7-T, as well as the negative-control combination of PGBKT7Lam and PGADT7-T, were individually transfected into the competent cells of yeast strain Y2H GOLD. SD/-Trp/ $\mathrm{X}-\alpha-\mathrm{Gal}$ and $\mathrm{SD} /-\mathrm{Trp} /-\mathrm{Leu} / \mathrm{X}-\alpha-\mathrm{Gal}$ medium was used to screen the bait transformants PGBKT7-VmD6PKL2 and the control transformants. In addition, the bait yeast strain Y2HGold containing PGBKT7-VmD6PKL2 and library yeast strain Y187 containing PGADT7-cDNA were mated and screened by SD/-Trp-Leu-His/X- $\alpha-G a l / A b A$ medium to identify the components that potentially interact with VmD6PKL2. The positive colonies were further cultured on SD/-Ade-Trp-Leu-His/X- $\alpha$-Gal/AbA medium, and the expression of the reporter gene LacZ was confirmed according to the blue color of the colony. 
Prey plasmids PGADT7-cDNA were extracted from positive blue colonies, which were further retransfected into Y2HGold possessing bait plasmid PGBKT7VmD6PKL2 for one-to-one-interaction screening. Inserted cDNA sequences in prey plasmids of positive colonies were sequenced and analyzed with the BLASTX program available at NCBI.

\section{GST pull-down assay}

The ORF sequences of VmBRXL4 and VmSYT3 were amplified from cDNA templates. The encoded amino acid sequences of these two genes were analyzed in the same way as D6PKL2. Then, the appropriate fragment of these two genes linking EcoR I and XhoI restriction sites was cloned into the prokaryotic expression vector PGEX-6P-1. Successfully constructed recombinant plasmids PGEXGST-VmSYT3 and PGEX-GST-VmBRXL4 were transformed into E. coli Rosetta for protein expression. IPTG was used to induce the high expression of GSTVmBRXL4 and GST-VmSYT3. The inclusion body proteins were purified, renatured, and finally analyzed using SDS-PAGE and western blotting assays.

Fifty nanograms of GST protein, as a control, and $30 \mu \mathrm{l}$ of strains expressing GST-VmSYT3 or GST-VmBRXL4, as test groups, were incubated with glutathione resinbound proteins for $1 \mathrm{~h}$ at $4{ }^{\circ} \mathrm{C}$. After incubation, the unbound proteins were removed by TBS buffer $(10 \mathrm{mM}$ Tris, $150 \mathrm{mM} \mathrm{NaCl}, \mathrm{pH} 8.0$ ) five times. Then, $50 \mu \mathrm{g}$ of total protein from the root tissue of $V$. montana was incubated with the control and test groups separately overnight at $4{ }^{\circ} \mathrm{C}$. The beads were then washed three times with TBS buffer and lysed by RIPA buffer $(50 \mathrm{mM}$ Tris-HCl, pH 8.0, $150 \mathrm{mM} \mathrm{NaCl}, 2 \mathrm{mM}$ EDTA, $1 \%$ NP-40, $0.5 \%$ sodium deoxycholate, $0.1 \%$ SDS) and $2 \times$ loading buffer $(100 \mathrm{mM}$ Tris- $\mathrm{HCl}, 200 \mathrm{mM}$ DTT, 4\% SDS, $0.2 \%$ bromophenol blue, 20\% glycerol). After boiling for $10 \mathrm{~min}$ and centrifugation of the lysate, the supernatant was collected. Finally, the pulled-down complexes were subjected to SDS-PAGE and analyzed by Western blot using antiGST $(1: 50,000)$ and antiD6PKL2 $(1: 1,000)$ antibodies.

\section{Accession numbers}

These sequence data have been submitted to the GenBank database under the accession numbers VmD6PKL2 (MN053921), VfD6PKL2 (MN053922), VmSYT3 (MN05 3923), VmBRXL4 (MN053925), VmABCI15 (MN053927), VmG6PD6 (MN053928) and VmHLB1 (MN053929). The GenBank address is www.ncbi.nlm.nih.gov/genbank.

\section{Acknowledgements}

The work was financially supported by the National Natural Science Foundation of China (31971685) and the Fundamental Research Funds for the Central Nonprofit Research Institution of Chinese Academy of Forestry (CAFYBB2019ZB002)

\section{Author contributions}

Y.C., Y.D., and Q.Y. designed the experiments; Q.Y. performed most of the experiments and analyzed the data; Z.L. conducted immunolocalization analysis; Y.X. drew the figures; L.W., H.F., M.G., and H.W. provided technical assistance; Q.Y. and Y.C. wrote the article with contributions from all the authors; Y.C. and Y.D. conceived the project, supervised the analysis and critically complemented the manuscript.

\section{Conflict of interest}

The authors declare no competing interests.

Supplementary information The online version contains supplementary material available at https://doi.org/10.1038/s41438-021-00656-2.

Received: 10 March 2020 Revised: 4 June 2021 Accepted: 13 June 2021 Published online: 01 November 2021

\section{References}

1. Dean, R. et al. The Top 10 fungal pathogens in molecular plant pathology. Mol. Plant Pathol. 13, 414-430 (2012).

2. Gordon, T. R. Fusarium oxysporum and the Fusarium wilt syndrome. Annu. Rev. Phytopathol. 55, 23-39 (2017).

3. Michielse, C. B. \& Rep, M. Pathogen profile update: Fusarium oxysporum. Mol. Plant Pathol. 10, 311-324 (2009).

4. Berrocal-Lobo, M. \& Molina, A. Arabidopsis defense response against Fusarium oxysporum. Trends Plant Sci. 13, 145-150 (2008).

5. Warman, N. M. \& Aitken, E. A. B. The Movement of Fusarium oxysporum f. sp. cubense (sub-tropical race 4). in susceptible cultivars of banana. Front. Plant Sci. 9, 1748 (2018).

6. Zhang, Q. et al. Expression network of transcription factors in resistant and susceptible tung trees responding to Fusarium wilt disease. Ind. Crops Products 122, 716-725 (2018).

7. Chen, Y. et al. Comparative transcriptomics atlases reveals different gene expression pattern related to Fusarium wilt disease resistance and susceptibility in two Vernicia species. Front. Plant Sci. 7, 1974 (2016).

8. Zhang, Q., Gao, M., Wu, L., Wang, Y. \& Chen, Y. Divergent expression patterns in two Vernicia species revealed the potential role of the hub gene VmAP2/ ERFO36 in resistance to Fusarium oxysporum in Vernicia montana. Genes (Basel) 7, E109 (2016).

9. Zvirin, T. et al. Differential colonization and defence responses of resistant and susceptible melon lines infected by Fusarium oxysporum race 1.2. Plant Pathol. 59, 576-585 (2010).

10. Recorbet, G. et al. Wanted: pathogenesis-related marker molecules for Fusarium oxysporum. N. Phytologist 159, 73-92 (2003).

11. Chen, Y. C. et al. Root defense analysis against Fusarium oxysporum reveals new regulators to confer resistance. Sci. Rep. 4, 5584 (2014).

12. Hanemian, M. et al. Arabidopsis CLAVATA1 and CLAVATA2 receptors contribute to Ralstonia solanacearum pathogenicity through a miR169-dependent pathway. N. Phytologist 211, 502-515 (2016).

13. Lorenc-Kukuła, K. et al. Engineering flax with the GT family 1 Solanum sogarandinum glycosyltransferase SsGT1 confers increased resistance to Fusarium infection. J. Agric. Food Chem. 57, 6698-6705 (2009).

14. Zhang, W., Chen, J., Zhang, H. \& Song, F. Overexpression of a rice diacylglycerol kinase gene OsBIDK1 enhances disease resistance in transgenic tobacco. Mol. Cells 26, 258-264 (2008).

15. Stanislas, T. et al. Arabidopsis D6PK is a lipid domain-dependent mediator of root epidermal planar polarity. Nat. Plants 1, 15162 (2015).

16. Willige, B. C. et al. D6PK AGCVIII kinases are required for auxin transport and phototropic hypocotyl bending in Arabidopsis. Plant Cell 25, 1674-1688 (2013).

17. Li, C. et al. The use of GFP-transformed isolates to study infection of banana with Fusarium oxysporum f. sp. cubense race 4. Eur. J. Plant Pathol. 131, 327-340 (2011).

18. Trujillo, E. E. \& Snyder, W. C. Uneven distribution of Fusarium oxysporum f. sp. cubense in Honduras soils. Phytopathology 53, 167 (1963).

19. Dita, M., Barquero, M., Heck, D., Mizubuti, E. S. G. \& Staver, C. P. Fusarium wilt of banana: current knowledge on epidemiology and research needs toward sustainable disease management. Front. Plant Sci. 9, 1468 (2018). 
20. Lee, B. H. et al. Arabidopsis protein kinase D6PKL3 is involved in the formation of distinct plasma membrane aperture domains on the pollen surface. Plant Cell 30, 2038-2056 (2018).

21. Galván-Ampudia, C. S. \& Offringa, R. Plant evolution: AGC kinases tell the auxin tale. Trends Plant Sci. 12, 541-547 (2007).

22. Garcia, A. V., Al-Yousif, M. \& Hirt, H. Role of AGC kinases in plant growth and stress responses. Cell. Mol. Life Sci. 69, 3259-3267 (2012).

23. Matsui, H., Miyao, A., Takahashi, A. \& Hirochika, H. Pdk1 kinase regulates basal disease resistance through the OsOxi1-OsPti1a phosphorylation cascade in rice. Plant Cell Physiol. 51, 2082-2091 (2010).

24. Rentel, M. C. et al. OXI1 kinase is necessary for oxidative burst-mediated signalling in Arabidopsis. Nature 427, 858-861 (2004).

25. Zhu, X. et al. The wheat AGC kinase TaAGC1 is a positive contributor to host resistance to the necrotrophic pathogen Rhizoctonia cerealis. J. Exp. Bot. 66, 6591-6603 (2015).

26. Zourelidou, M. et al. Auxin efflux by PIN-FORMED proteins is activated by two different protein kinases, D6 PROTEIN KINASE and PINOID. Elife 3, e02860 (2014).

27. Robert-Seilaniantz, A., Grant, M. \& Jones, J. D. Hormone crosstalk in plant disease and defense: more than just jasmonate-salicylate antagonism. Annu. Rev. Phytopathol. 49, 317-343 (2011).

28. Ruonala, R., Ko, D. \& Helariutta, Y. Genetic networks in plant vascular development. Annu. Rev. Genet. 51, 335-359 (2017).

29. Tian, H., Lv, B., Ding, T., Bai, M. \& Ding, Z. Auxin-BR interaction regulates plant growth and development. Front. Plant Sci. 8, 2256 (2018).

30. Zourelidou, M. et al. The polarly localized D6 PROTEIN KINASE is required for efficient auxin transport in Arabidopsis thaliana. Development 136, 627-636 (2009).

31. Levy, A., Zheng, J. Y. \& Lazarowitz, S. G. Synaptotagmin SYTA forms ER-plasma membrane junctions that are recruited to plasmodesmata for plant virus movement. Curr. Biol. 25, 2018-2025 (2015).

32. Martens, S., Kozlov, M. M. \& McMahon, H. T. How synaptotagmin promotes membrane fusion. Science 316, 1205-1208 (2007).

33. Yamazaki, T., Takata, N., Uemura, M. \& Kawamura, Y. Arabidopsis synaptotagmin SYT1, a type I signal-anchor protein, requires tandem C2 domains for delivery to the plasma membrane. J. Biol. Chem. 285, 23165-23176 (2010).

34. Yang, T. \& Poovaiah, B. W. Calcium/calmodulin-mediated signal network in plants. Trends Plant Sci. 8, 505-512 (2003).

35. Lecourieux, D., Ranjeva, R. \& Pugin, A. Calcium in plant defence-signalling pathways. N. Phytologist 171, 249-269 (2006).

36. Blumwald, E., Aharon, G. S. \& Lam, B. C. H. Early signal transduction pathways in plant-pathogen interactions. Trends Plant Sci. 3, 342-346 (1998).

37. Kim, H. et al. Synaptotagmin 1 negatively controls the two distinct immune secretory pathways to powdery mildew fungi in Arabidopsis. Plant Cell Physiol. 57, 1133-1141 (2016).

38. Stolarczyk, E. I., Reiling, C. J. \& Paumi, C. M. Regulation of ABC transporter function via phosphorylation by protein kinases. Curr. Pharm. Biotechnol. 12, 621-635 (2011).
39. Cohen, P. The role of protein phosphorylation in human health and disease Eur. J. Biochem. 268, 5001-5010 (2001).

40. Weller, B. et al. Dynamic PIN-FORMED auxin efflux carrier phosphorylation at the plasma membrane controls auxin efflux-dependent growth. Proc. Nat Acad. Sci. 114, E887-E896 (2017).

41. Withers, J. \& Dong, X. Post-translational regulation of plant immunity. Curr. Opin. Plant Biol. 38, 124-132 (2017).

42. Hu, Y., You, J., Li, J. \& Wang, C. Loss of cytosolic glucose-6-phosphate dehydrogenase increases the susceptibility of Arabidopsis thaliana to root-knot nematode infection. Ann. Bot. 123, 37-46 (2018).

43. Stampfl, H., Fritz, M., Dal Santo, S. \& Jonak, C. The GSK3/Shaggy-like kinase ASKa contributes to pattern-triggered immunity. Plant Physiol. 171, 1366-1377 (2016).

44. Dal Santo, S. et al. Stress-induced GSK3 regulates the redox stress response by phosphorylating glucose-6-phosphate dehydrogenase in Arabidopsis. Plant Cell 24, 3380-3392 (2012).

45. Do, T. H. T., Martinoia, E. \& Lee, Y. Functions of ABC transporters in plant growth and development. Curr. Opin. Plant Biol. 41, 32-38 (2018).

46. Hwang, J. U. et al. Plant $A B C$ transporters enable many unique aspects of a terrestrial plant's lifestyle. Mol. Plant 9, 338-355 (2016).

47. Bienert, M. D. et al. A pleiotropic drug resistance transporter in Nicotiana tabacum is involved in defense against the herbivore Manduca sexta. Plant J. 72, 745-757 (2012).

48. Campe, R. et al. ABC transporter PEN3/PDR8/ABCG36 interacts with calmodulin that, like PEN3, is required for Arabidopsis nonhost resistance. N. Phytologist 209, 294-306 (2016).

49. Krattinger, S. G. et al. A putative $A B C$ transporter confers durable resistance to multiple fungal pathogens in wheat. Science 323, 1360-1363 (2009).

50. Zhang, X., Henriques, R., Lin, S., Niu, Q. W. \& Chua, N. H. Agrobacteriummediated transformation of Arabidopsis thaliana using the floral dip method. Nat. Protoc. 1, 641 (2006).

51. Vrljic, M. et al. Molecular mechanism of the synaptotagmin-SNARE interaction in $\mathrm{Ca}^{2+}$-triggered vesicle fusion. Nat. Struct. Mol. Biol. 17, 325 (2010).

52. Marhava, P. et al. A molecular rheostat adjusts auxin flux to promote root protophloem differentiation. Nature 558, 297-300 (2018).

53. Peele, H. M. Defense Gene Responses Toward Necrotrophic Fungi in Arabidopsis thaliana. PhD thesis, Swedish University of Agricultural Sciences, Uppsala, Sweden (2015)

54. Sparks, J. A. et al. HLB1 is a tetratricopeptide repeat domain-containing protein that operates at the intersection of the exocytic and endocytic pathways at the TGN/EE in Arabidopsis. Plant Cell 28, 746-769 (2016).

55. Rasband, W. S. ImageJ, U. S. National Institutes of Health, Bethesda, Maryland. https://imagej.nih.gov/ij/ (1997-2020).

56. Pavicic, M. et al. Image-based methods to score fungal pathogen symptom progression and severity in excised Arabidopsis leaves. Plants (Basel) 10, 158 (2021). 